\title{
Assessment of Functional Lung Impairment in Hypothyroidism
}

\author{
Sharon Roel*, O. Punyabati*, Lallan Prasad**, Ranabir Salam**, \\ Kanmi Ningshen*, A. Jannie Shimray*, Merrycka A. Sangma*, \\ Hongprachan Hungyo*, Ashem Nandarani Devi* \\ Department of Physiology*, Department of Medicine** RIMS, Imphal, Manipur.
}

\begin{abstract}
:
Aims: To determine any functional lung impairment amongst patients diagnosed with hypothyroidism by spirometry. Methods: 21 hypothyroid subjects with TSH $\geq 10 \mathrm{mIU} / \mathrm{L}$ aged between 18-52 yrs were studied along with 21 healthy controls in the department of Physiology, Regional Institute of Medical Sciences (RIMS), Imphal. Hypothyroid subjects with other conditions/diseases which affect PFT were excluded. Spirometric parameters were conducted by means of computerised spirometer HELIOS 401/701(RMS, Chandigarh). The

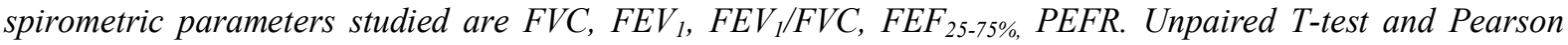
correlation was used and $P$ value $<0.05$ was taken as significance. Result: Hypothyroid subjects showed a

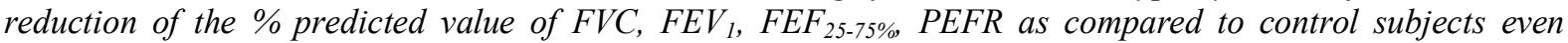
though these values are within the normal values for their age, sex and gender. But the difference is statistically significant only for FVC. And the \% predicted value for FEV $/ F V C$ of hypothyroid subjects is found to be significantly increased than the controls. On analyzing and classifying only the hypothyroid subjects based on FVC values, $47 \%$ of the hypothyroid subjects were normal while 9\% had mild restrictive lung impairment and the rest $43 \%$ had moderate to severe restrictive impairment. A negative correlation was found between TSH levels with the spirometric parameters $F V C, F E V_{1}, F E V 1 / F V C$ and a positive correlation was found between $T_{4}$ levels with $\mathrm{FVC}, \mathrm{FEV}, \mathrm{FEV} / \mathrm{FVC}$. But none of the findings were not statistically significant. Conclusion: The pulmonary functions can be affected in hypothyroidism and they show a restrictive pattern of lung impairment.
\end{abstract}

Keywords: Spirometer, hypothyroidism, FVC, FEV,$F E V_{1} / F V C$

\section{Introduction}

Hypothyroidism is a relatively common problem worldwide often with insidious onset and is relatively asymptomatic. Respiratory manifestations are seldom the major complaints in hypothyroidism. ${ }^{[1]}$ Lung volumes are usually normal, but few studies have shown findings suggestive of restrictive pattern of impairment. This has been attributed to decreased in both expiratory and inspiratory muscle strength, alveolar hypoventilation due to depression of hypoxic and hypercapnic ventilatory drives and decreased in maximal breathing and diffusing capacity in patients with hypothyroidism. ${ }^{[2-4,7]}$ Weight gain independently of physical activity is frequently associated with hypothyroidism. ${ }^{[5]}$ Most of the restrictive defects seen among these patients has been thought to be a consequence of obesity and microatelectesis. ${ }^{[1]}$ Overt thyroid dysfunction is well recognized to affect weight, but the influence of minor perturbations of thyroid function remains unclear. ${ }^{[5,6]}$

In this study, spirometry was done to determine any functional lung impairment in hypothyroid patients and to compare with control subjects who are matched for their age and sex. BMI and body fat percentage was also analysed to determine if it has any contribution to the lung impairment if it is indeed present. And also to determined if there is any correlation between the thyroid function with the pulmonary function among the study population.

\section{Materials and methods}

A cross sectional study done with 21 hypothyroid patients with $\mathrm{TSH} \geq 10 \mathrm{mIU} / \mathrm{L}$ and 21 apparently healthy subjects within the age groups of 18-52 yrs. It was conducted in the department of Physiology, Regional Institute of Medical Sciences (RIMS), Imphal with the patients recruited from the Medicine Department. Patients with associated conditions which affect pulmonary function test were excluded. Written informed consent was obtained from the participients. The Institutional ethical committee approval was also taken.

All thyroid function tests were performed in one laboratory centre. TSH, free T4 and free T3 were measured by Chemiluminescence. FVC, FEV $1, \mathrm{FEV}_{1} / \mathrm{FVC}$, PEFR, FEF ${ }_{25-75 \%}$ recorded by computerised Spirometer- Helios 401/701 (RMS, Chandigarh). BMI and body fat \% was analysed by Tanita Innerscan Body Composition Monitor using the principle of bioelectrical impedence. Statistical analysis was done with SPSS16. Unpaired T-test and Pearson correlation used and $\mathrm{P}$ value $<0.05$ was taken as significance. 


\section{Results}

The basal parameters of the study population is depicted in table 1 along with BMI and body fat percentage. The hypothyroid group comprised of $81 \%$ female \& $19 \%$ male with mean age of $36.6 \pm 11.40$ years. And the control group comprised of $76 \%$ female \& $24 \%$ male with mean age of $39.95 \pm 10.65$ years. There was no significant difference between the two groups in these parameters. And there was also no significant difference in the BMI and body fat percentage between the two groups as well.

TABLE 1: Baseline characteristics of the study population

\begin{tabular}{|l|l|l|l|}
\hline Parameters & Hypothyroids (21) & Controls(21) & P value \\
\hline AGE(yrs) & $36.6 \pm 11.4$ & $39.95 \pm 10.65$ & 0.331 \\
\hline ILLNESS(mths) & $14.8 \pm 9.4$ & -- & -- \\
\hline TSH(mIU/L) & $59.21 \pm 58.88$ & $2.55 \pm 1.44$ & $0.000^{* *}$ \\
\hline fT4 $(\mathrm{ng} / \mathrm{dl})$ & $2.95 \pm 1.27$ & $8.17 \pm 2.26$ & $0.000^{* *}$ \\
\hline BMI $\left(\mathrm{Kg} / \mathrm{m}^{2}\right)$ & $24.02 \pm 4.4$ & $23.33 \pm 2.06$ & 0.516 \\
\hline BODY FAT \% & $27.7 \pm 9.8$ & $26.85 \pm 6.43$ & 0.718 \\
\hline
\end{tabular}

$\mathrm{P}$ value $<0.05$ significance*; $<0.005$ highly significant**

The hypothyroid subjects have much higher TSH and lower T4 levels as compared to that of the controls and the difference was found to be statistically significant. And the mean average duration of illness of the hypothyroid subjects was $14.8 \pm 9.4$ months.

TABLE 2: Spirometric findings of study population given in predicted \% values

\begin{tabular}{|l|l|l|l|}
\hline Parameters & Hypothyroids (21) & Controls(21) & P value \\
\hline FVC\% & $81.53 \pm 19.39$ & $93.72 \pm 11.03$ & $0.016^{*}$ \\
\hline FEV $_{1} \%$ & $97.09 \pm 23.92$ & $102.95 \pm 16.85$ & 0.365 \\
\hline FEV $_{1} / \mathrm{FVC}_{\%}$ & $118.53 \pm 4.75$ & $106.15 \pm 20.79$ & $0.011^{*}$ \\
\hline PEFR $\%_{\text {FEF }_{25-75 \%}} \%$ & $83.34 \pm 20.16$ & 0.77 \\
\hline
\end{tabular}

$\mathrm{P}$ value $<0.05$ significance*

The spirometric findings of both hypothyroid subjects and controls are given in table 2 and are expressed in predicted percentage. The mean $\mathrm{FVC}, \mathrm{FEV}_{1}, \mathrm{PEFR}, \mathrm{FEF}_{25-75 \%}$ values are all comparatively decreased as compared to the controls even though these values are within the normal values for their age, sex and gender. But the difference is statistically significant only for FVC. The mean $\mathrm{FEV}_{1} / \mathrm{FVC}$ ratio is found to be increased in comparison to the controls and this ratio is found to be statistically significant. Other parameters PEFR and FEF25-75\% were also decreased among the hypothyroids as compared to the controls though it was not found to be statistically significant. This table is also represented in the form of bar diagram in figure 1 .

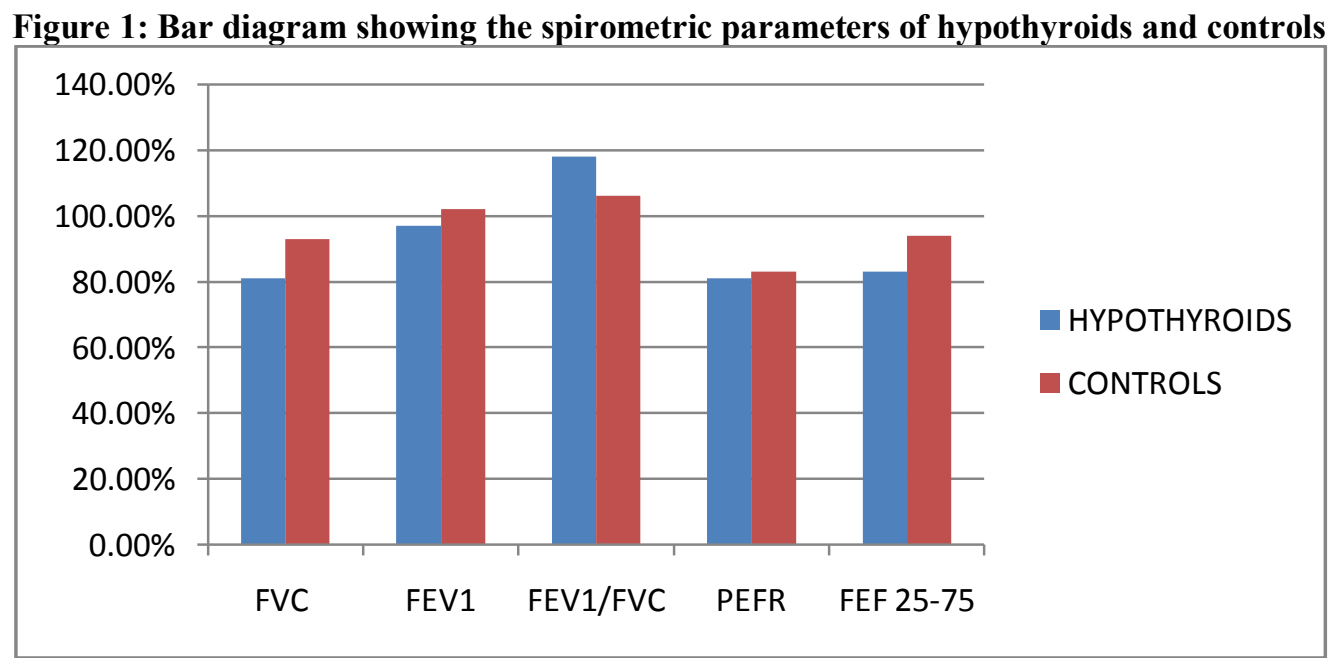

On analyzing and classifying only the hypothyroid subjects as per the American Thoracic Society (ATS) guidelines ${ }^{[12]}, 47 \%$ of the hypothyroid subjects were normal while $9 \%$ had mild restrictive lung impairment and the rest $43 \%$ had moderate to severe restrictive impairment as depicted in the figure 2. 
FIGURE 2: Grouping of the hypothyroid subjects in terms of FVC \% predicted values

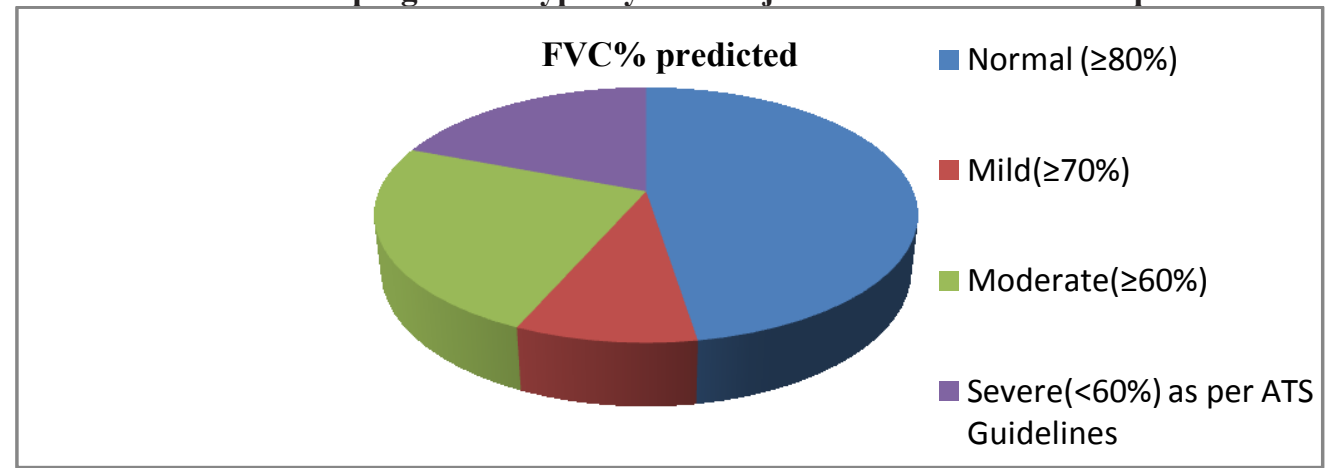

There is negative correlation between TSH levels with the spirometric parameters FVC, FEV $\mathrm{FEV}_{1} / \mathrm{FVC}$. But a positive correlation between $\mathrm{T}_{4}$ levels with $\mathrm{FVC}, \mathrm{FEV}_{1}, \mathrm{FEV}_{1} / \mathrm{FVC}$. But none of these findings were not statistically significant as depicted on table 3.

Table 3: TSH and T4 correlations with FCV,FEV, FEV / FVC among the hypothyroid subjects

\begin{tabular}{|l|l|l|}
\hline Parameters & TSH & T4 \\
\hline FVC(Ltrs) & -0.334 & +0.256 \\
\hline FEV $_{1}$ Ltrs) & -0.363 & +0.291 \\
\hline FEV $_{1} / \mathrm{FVC} \%$ & -0.172 & +0.167 \\
\hline
\end{tabular}

Not statistically significant

\section{Discussion}

Hypothyroidism can have numerous effects on the respiratory system. Fatigue and dyspnoea on exertion are frequent symptoms. But in the absence of primary respiratory disease, the dimunition of the respiratory function in the hypothyroid patients is not significant in most cases. ${ }^{[1]}$

Nevertheless, it does affect the respiratory system including respiratory muscle weakness, alveolar hypoventilation due to decreased hypoxic and hypercapnic ventilatory drives, upper airway obstruction, central and obstructive sleep apnoea and even pleural effusion. Lung volumes are usually normal or mildly reduced, but maximal breathing capacity and diffusing capacity are usually reduced. ${ }^{[7]}$

In our study, $\mathrm{FVC} \& \mathrm{FEV}_{1}$ values were found to be lower in hypothyroids as compared with controls but it was significant only for FVC. This is in accordance with other study conducted by Valjevac $\mathrm{S}$ et $\mathrm{al}^{\left[{ }^{[8]}\right.}$ who demonstrated decreased in FVC and $\mathrm{FEV}_{1}$ among the hypothyroid subjects and suggested that the degree and the duration of thyroid disorders lead to reduced ventilator lung function in patients with thyroid dysfunction. In other studies, there was a significant difference in the lung functions between those subjects not on treatment and those on thyroid hormone replacement therapy and the decreased in these spirometric parameters in hypothyroidism can be corrected by hormone replacement therapy. ${ }^{[4,9,10,11]}$

Cakmak $\mathrm{G}$ et al ${ }^{[4]}$ observed a significant reduction in $\mathrm{FVC}, \mathrm{FEV}_{1}, \mathrm{FEV}_{1} \%, \mathrm{FEF}_{25-75}, \mathrm{FEF}_{25-75 \%}$ and DLCO in patients with subclinical hypothyroidism as compared with control subjects. Sharifi $\mathrm{F}^{[1]}$ et al reported about $87 \%$ of restrictive abnormality ranging from mild to moderate grade amongst the hypothyroid subjects which improved significantly on treatment.

The $\mathrm{FEV}_{1} / \mathrm{FVC}$ value is significantly increased among the hypothyroid subjects as compared to controls. This together with the decreased in FVC suggests that there is a mild restrictive pattern among the hypothyroid subjects even though the changes in these specific spirometric parameters are not that extreme so as to suggest a diagnosis of restrictive lung disease as per the ATS guidelines. ${ }^{[12]} 47 \%$ of the hypothyroid subjects were normal while the rest had some restrictive defects ranging from mild to severe lung impairment. One study reported hypothyroidism with hypoxia associated with computed tomographic features suggestive of pulmonary fibrosis that resolved with correction of the hypothyroidism and suggested that fibrotic disease leading to restrictive abnormality can be associated with severe hypothyroidism. ${ }^{[13]}$

Analysis of changes in pulmonary function is complicated by increased frequency of overweight or obesity in hypothyroid patients. Abnormalities attributed in the literature to hypothyroidism actually may have been due to obesity. ${ }^{[1]}$ But in our study, the average BMI \& body fat $\%$ of the hypothyroid patients are $24.02 \pm 4.4 \mathrm{~kg} / \mathrm{m}^{2} \& 27.7 \pm 9.8 \%$ respectively \& this are within the recommended range for their age, sex and 
gender (Based on NIH/WHO guidelines). And there is no significant difference in terms of the BMI and body fat percentage between the hypothyroid subjects and the controls. Hence, the additive effects of obesity on spirometeric parameters can be ruled out.

On analyzing any correlation between the thyroid hormone levels and the pulmonary function amongst the subjects, it is found that there is an inverse correlation between TSH levels with the spirometric parameters FVC, FEV 1 , FEV1/FVC. But a positive correlation was found between T4 levels with FVC, FEV 1 , FEV $/$ /FVC. But none of these findings were not statistically significant. These findings are similar with study conducted by Cakmak et $\mathrm{al}^{[4]}$ in which they found negative correlation between TSH levels with $\mathrm{FVC}, \mathrm{FEF}_{25-75 \%}$ and positive correlation between $\mathrm{T}_{4}$ levels with FCV only.

The decreased in all the values for spirometric parameters in hypothyroid subjects maybe attributed to low serum $\mathrm{T}_{4}$ which may cause inspiratory muscle power weakness and hypoventilation.

\section{Conclusion}

There is a significantly reduction in the dynamic lung functions of hypothyroid subjects as compared with controls. Respiratory system can be affected in hypothyroidism. Simple spirometry can be considered as a means for evaluation of pulmonary functions in these patients.

\section{References}

[1]. Braverman LE, Utiger RD. Introduction to hypothyroidism. In: Braverman LE, Utiger RD, Werner SC, Ingbar SH,editors. The thyroid: A fundamental and clinical text. $9^{\text {th }}$ Ed. Philadelphia: Lippincott Williams and Wilkins; 2005. p.697-9.

[2]. Zwillich CW, Pierson PJ, Hofeldt FD, Lufkin EG, Weil JV. Ventilatory control in myxedema and hypothyroidism. N Engl J Med 1975; 292: 662-5.

[3]. Siafakas NM, Salesiotou V, Filaditaki V, Tzanakis N, Thallassinos N, Bouros D. Respiratory muscle strength in hypothyroidism. Chest 1992; 102(1): 189-94.

[4]. Cakmak G, Saler T, Saglam Z, Yenigen M, Demir T. Spirometry in paients with clinical and subclinical hypothyroidism. Tüberküloz ve Toraks Dergisi 2007; 55(3): 266-70.

[5]. Biondi B. Thyroid and obesity: An intriguing relationship. J Clin Endocrinol Metab 2010 Aug; 95(8): $3614-7$.

[6]. Salome CM, King GG, Berend N. Physiology of obesity and effects on lung function. J Appl Physiol 2010; 108: 206-11.

[7]. Brent GA, Davies T. Hypothyroidism and Thyroiditis. In: Melmed S, Polonsky KS, Larsen PR, Kronenberg HM, Editors.Williams Text book of Endocrinology. 12th ed. Philadelphia WB. Saunders Co, 2011. p.409.

[8]. Valjevac S, Hadzovic-Dzuvo A, Valjevac A, Kucukalic-selimovic E, Lepara O. Assesement of lung dysfunction with spirometry in patients with thyroid Disorders. Acta inform med 2011 Mar; 19(1): 16-8.

[9]. Martinez FJ, Bermudez-Gomez M, Celli BR. Hypothyroidism: A reversible cause of diaphragmatic dysfunction. Chest 1989; 96(5): 1059-63

[10]. Bassi R, Dhillon SK, Sharma S, Sharma A, Tapdiya M. Effect of thyroid hormone replacement on respiratory function tests in hypothyroid women. Pak J Physiol 2012;8(2): 20-23.

[11]. Sharifi F, Amari A. The effect of levothyroxin on pulmonary function tests of hypothyroid patients. Int J Endocrinol Metab 2005; $1: 48-51$.

[12]. American Thoracic Society. Lung function testing: selection of reference values and interpretative strategies. Am Rev Respir Dis 1991; 144: 1202-1218

[13]. George JT, Thow JC, Rodger KA, Mannion R, Jayagopal V. Reversibility of fibrotic appearance of lungs with thyroxine replacement therapy in patients with severe hypothyroidism. Endocr Pract. 2009 Nov-Dec;15(7):720-4. 